Transportation Management (2018) Volume 1

doi:10.24294/tm.v1i4.524

\title{
The Effects of Interest Rates on the Valuation of Highway Infrastructure Assets
}

\section{Carles Vergara-Alert}

Financial Management Department, IESE Business School, University of Navarra; E-mail: CVergara@iese.edu

\begin{abstract}
The discounted value of cash flows of assets is negatively related to interest rates (i.e., the discount rate effect). However, economic activity is positively related to interest rates and positively related to the cash flows of assets with tariffs that can be adjusted to manage demand such as adjustable-rate toll roads, but uncorrelated to assets that do not bear demand risk such as non-toll roads (i.e., the cash flow effect). This effect arises in some types of assets from: (i) the positive correlation between economic activity and demand for the infrastructure assets; and (ii) the positive correlation between economic activity and inflation. We find that the cash flow effect dominated the discount rate effect for assets with tariffs that can be adjusted to manage demand and, therefore, the value of these assets increases in periods of economic expansion. Nevertheless, the opposite occurs for assets that do not bear demand risk.

Keywords: Transportation Infrastructure; Highways Valuation; Interest Rates; Multivariate VAR Analysis; Model Parameterization
\end{abstract}

\section{Introduction}

The valuation of any asset that produces cash flows is affected by the dynamics of interest rates. Specifically, the value of an asset that produces a given stream of cash flows decreases when interest rates increase because this stream of expected cash flows is discounted at a higher discount rate. Therefore, ceteris paribus, the discounted value of cash flows of assets is negatively related to interest rates. We denote this relationship as the discount rate effect.

Since a large amount of infrastructure assets present cash flows that are uncorrelated (e.g., constant) or with little correlation with interest rates (e.g., tariffs adjusted according to a concession contract), investors could imply that an increase in interest rates would cause a decline in the value of infrastructure assets. However, many infrastructure assets present a stream of cash flows that is positively related to the dynamics of interest rates. This is due to the fact that periods of increasing interest rates are usually related to economic expansions and, therefore, periods of growth in tariffs and traffic, which increase the cash flows of the infrastructure asset. Therefore, ceteris paribus, the discounted value of cash flows of assets is positively related to economic activity (e.g., detrended GDP), which is positively connected to interest rates. We denote this positive relationship between cash flows and the value of the asset as the cash flow effect.

In this paper, we show that the negative relationship between interest rates and the value of infrastructure assets is only present in infrastructures in which the discount rate effect dominates the cash flow effect, that is, in infrastructures in which the cash flows do not grow in a substantial amount in periods of increasing interest rates. There are many infrastructures in which the cash flow effect dominates the discount rate effect and, therefore, there is a positive relationship between interest rates and the value of infrastructure assets.

We specifically analyze the effect of interest rates in the value of the 5 types of highway infrastructure assets according to the payments that they obtain:

i. Category 1: Infrastructure assets with total fixed payments and no price adjustments. The Government periodically pays a predetermined fixed amount. This type of assets does not bear demand risk because the total fixed payments do not depend on the use of the asset. A non-toll road in which the Government pays a fixed amount to a firm that 
operates a private concession on the road is an example of a Category 1 asset.

ii. Category 2: Infrastructure assets with total fixed payments and inflation-adjusted prices. The Government periodically pays a predetermined inflation-adjusted amount. This type of assets does not bear demand risk because the total fixed payments do not depend on the use of the asset. A non-toll road in which the Government pays a fixed amount that is periodically adjusted with inflation to a firm that operates a private concession on the road is an example of a Category 2 asset.

iii. Category 3: Infrastructure assets with a pay-per-use pre-fixed inflation-adjusted tariff. This type of assets bears demand risk. A toll road in which users pay a pre-fixed toll rate amount that is periodically adjusted with inflation is an example of a Category 3 asset.

iv. Category 4: Infrastructure assets with a pay-per-use escalated tariff. The scale of tariffs is determined in terms of economic activity (e.g., GDP per capita) and there is usually a maximum value for the tariff increase. This type of assets bears demand risk. A toll road in which users reimburse a pay-per-use escalated toll that is periodically adjusted with respect to changes in the economic activity is an example of a Category 4 asset.

v. Category 5: Infrastructure assets with a free adjustable-rate tariff mechanism subject to a certain level of service. This type of assets bears demand risk and the operator of the infrastructure can raise or decrease the tariffs according to the willingness-to-pay of the users. Specifically, notice that the tariffs for the use of this type of infrastructure assets can increase above the inflation rate of the economy. A toll road in which users reimburse a pay-per-use toll that is used to manage its demand is an example of a Category 5 asset.

We first focus on the discount rate effect, which is the effect of the discount rate at which we discount cash flows to obtain an estimation of the value of an infrastructure asset. Because the relationship between economic activity and interest rates is positive, ceteris paribus the discounted value of cash flows of assets is negatively correlated to economic activity. In other words, higher interest rates usually lead to higher discount rates, which provide lower present value of future cash flows.

We also study the cash flow effect, which is the effect of interest rates and economic activity on the value of infrastructure assets. Because economic activity (e.g., GDP growth) is positively correlated to the cash flows of assets with tariffs that can be adjusted to manage demand (e.g., category 5 assets), but uncorrelated to assets that do not bear demand risk (e.g., category 1 assets), an increase in economic activity increases the cash flows of the former but not the later type of assets. This effect arises in some types of infrastructures assets from two sources. First, the positive correlation between economic activity and demand for infrastructure assets increases their cash flows, that is, the number of users of the infrastructure asset increases in periods of economic expansion. Second, the positive correlation between economic activity and prices of goods and services increases the cash flows of infrastructure assets. For example, the tariffs that users pay for the use of an infrastructure asset tend to increase in periods of economic expansion. This price increase is in play because supply cannot account for the shock in demand derived from the economic expansion. Notice that tariffs will increase above inflation in infrastructure assets of category 5 in which supply is inelastic (e.g., most of transportation infrastructure assets) because the operators of these assets may raise tariffs according to the high willingness-to-pay in periods of economic expansion.

We develop an econometric analysis and we find that the cash flow effect dominates the discount rate effect for assets with tariffs that can be adjusted to manage demand (e.g., category 5 assets). Therefore, the value of these assets increases in periods of economic expansion. Nevertheless, the opposite result occurs for assets that do not bear demand risk (e.g., category 1 assets), in which the value of these assets decreases.

The reminder of the paper is organized as follows. In section 2, we describe the macroeconomic framework that rationalizes the relationships among inflation, interest rates and GDP and the effect of monetary policy on these variables. Section 3 provides an econometric analysis of the joint effects of economic activity in Canada (i.e., Canadian inflation, GDP growth, nominal interest rates, and real interest rates) and the revenue growth of a category 5 infrastructure in Canada: highway 407 ETR. Section 4 studies a valuation model of highway infrastructure assets and 
compare the effects of economic activity on the 5 categories of infrastructure assets described above on their values. Finally, section 5 concludes.

\section{The macroeconomic framework: monetary policy, interest rates, inflation, GDP, and exchange rates}

Monetary authorities such as the Federal Reserve, the European Central Bank, the Bank of England, the Bank of Canada, and other central banks, influence interest rates and, indirectly they affect employment rates, the output gap, and inflation. The monetary transmission mechanism is the process that links the monetary policy to the performance of the economy. Monetary policy is referred to the actions of central banks. The performance of the economy is measured in terms of indicators such as the real gross domestic product (GDP), the output gap, and inflation. Central banks respond to the economic performance with their monetary policies, which affect the short-term nominal interest rates and closes the circle. Figure 1 summarizes this cyclical process that goes from the performance of the economy, to the monetary policy of the central bank, and the transmission of this monetary policy back to the economy. This figure also displays how this cycle affects infrastructure assets.

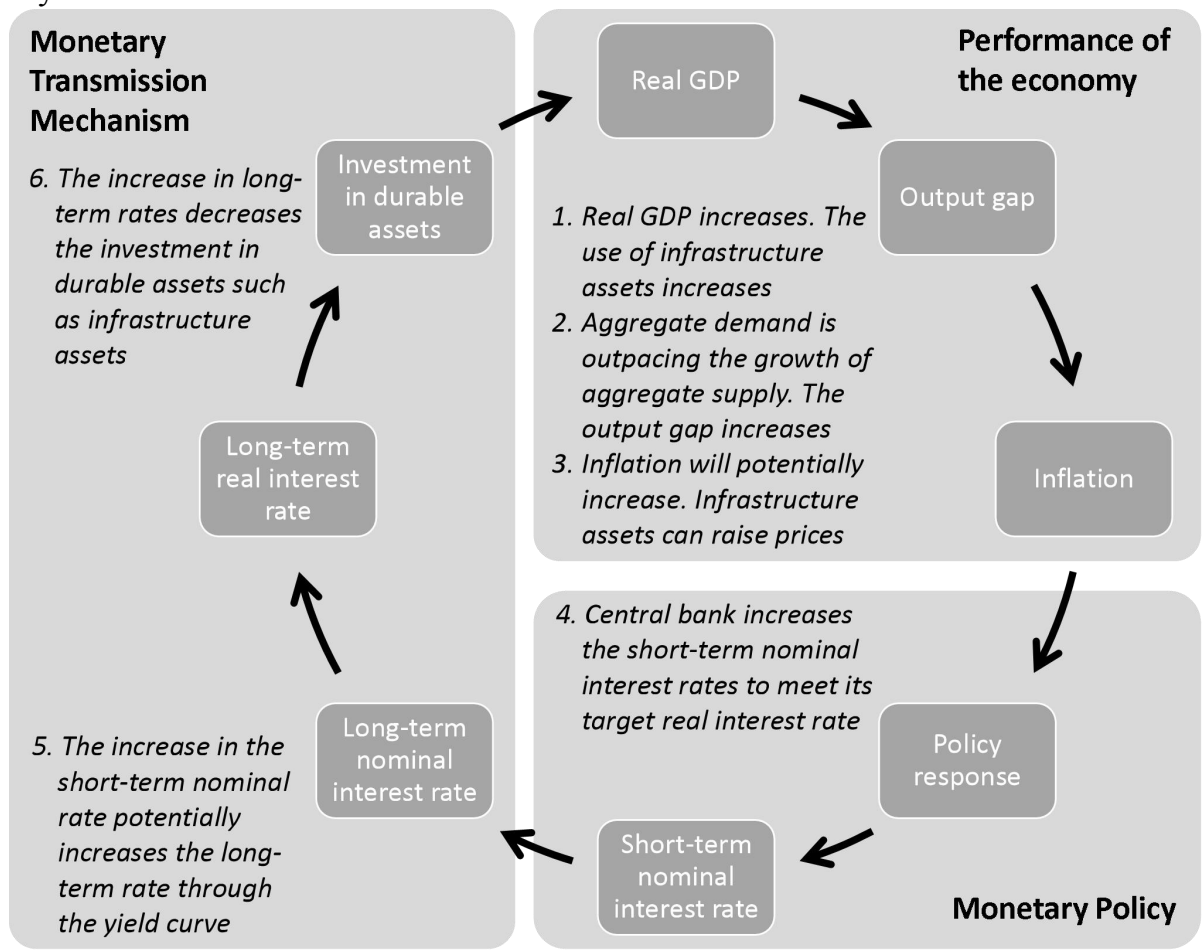

Figure 1; Performance of the economy, monetary policy, and its transmission. This figure shows how a shock in the real GDP affects interest rates through inflation, monetary policy and the monetary transmission mechanism.

The monetary transmission mechanism shows the effects of monetary policy in the macroeconomic variables, in particular the real GDP. It explains how the central bank's target interest rate (i.e., the short-term nominal interest rate) affects different interest rates in the economy and, consequently, how it affects investments. This mechanism goes as follows. The central bank operates in the financial markets to target a specific short-term nominal interest rate, which affects the long-term nominal interest rate through the yield curve or term structure of interest rates. This leads to a change in the long-term real interest rate, which in turn has an effect on long-term investments, such as investments in durable goods and infrastructure assets. Finally, these changes in investments affect the real GDP. 




Figure 2; Monetary policy, inflation, interest rates, and GDP. This figure summarizes the economic theory behind the monetary transmission mechanism.

Figure 2 summarizes in economic terms the monetary transmission mechanism developed in figure 1 and rationalizes how central banks adjust inflation. Let us assume that the economy is in a period of expansion, the real GPD is high (i.e., the output at time t-1 is high), and as a result, inflation, it-1, is high (point 1 of this figure). The central bank implements its rules such as a Taylor-type of model (point 2) and increases the short-term nominal interest rate to target an increase of real interest rate from $\mathrm{rt}-1$ to $\mathrm{rt}$ (point 3). This real interest rate increase should decrease inflation from it-1 to it (point 4) at the expenses of a reduction of the real GDP from outputt to outputt-1 (point 5). In summary, if the economy is in a period of expansion and inflation is high, the central bank will most likely increase the short-term nominal interest rate, which will decrease the real GDP. The three graphs in figure 2 also display the three relationships among the three main variables that drive the standard macroeconomic policy research models: the real GDP, the real interest rate, and inflation.

Positive relationship between inflation and the real interest rate. (Top left graph in figure 2). When inflation increases, the central bank raises the short-term nominal interest rate. This increase in the nominal interest rate should be enough to raise the real interest rate. The goal of the central bank with this action is to stop inflation from raising and make it decrease (see Taylor, 1999).

Negative relationship between real GDP and the real interest rate. (Top right graph in figure 2). As discussed in Taylor (2000), higher real interest rates reduce the demand for goods and services in the economy, because higher real interest rates dissuade investments and decreases consumption, which reduces demand and the real GDP.

Positive relationship between inflation and real GDP. (Bottom right graph in figure 2). In a standard expectations-augmented Phillips curve, inflation increases when real GDP rises above the potential GDP. The increase in real GDP signals a positive demand shock.

There is a vast body of literature that studies the direct relationship between interest rates and inflation. In an efficient capital market without uncertainty, the one-period nominal interest rate is the equilibrium real interest rate plus the fully expected inflation rate (Fisher, 1930). The initial point of view in theoretical economics was that changes in short-term interest rates reflect fluctuations in expected inflation. In other words, short-term interest rates are positively correlated with future inflation. This relationship is commonly known as the Fisher effect (see Fisher, 1930; Fama, 1975; Nelson and Schwert, 1977; Mishkin, 1981; Mishkin, 1988; and Fama and Gibbons, 1982). 
However, empirical evidence shows that the Fisher effect is not robust to different time periods or countries. Several studies in the 1970s and 80s documented the failure of the short-run Fisher effect in which changes in interest rates are related to changes in expected inflation (see Barsky, 1987; Mishkin, 1981; Summers, 1983; Huizinga and Mishkin, 1984; and Huizinga and Mishkin, 1986). A few years later, Mishkin (1992) demonstrated the existence of a long-run Fisher effect in which inflation and interest rates present a common stochastic trend when both variables exhibit trends, that is, when they are cointegrated. As a result, only if inflation and interest rates exhibit trends, then these two variables trend with a positive relationship and we observe a strong Fisher effect in the data. Lee (1992) developed a multivariate vector-autoregression (VAR) model to show that interest rates explain a substantial fraction of the variation in inflation, while inflation does not explain the variation in real activity. In summary, the Fisher effect is stated as the positive long-run relationship between inflation and interest rates.

Positive relationship between the real interest rate and the real exchange rate. The exchange rate is part of the transmission mechanism in monetary policy because net exports and, therefore, GDP depend on it. The exchange rate enters as part of a no-arbitrage condition that relates the interest rate in one country to the interest rates in other countries through the expectation about the exchange rate in the future. The exchange rate has an effect on the flow of imports and export and the relationship between the real interest rate and the real exchange rate is positive (see Mendoza, 1995; Kamin and Rogers, 2000).

Taylor (2001) develops the theory behind this positive relationship. He shows that there is an indirect effect between these two variables even if the central bank follows a policy rule that does not include a direct exchange rate effect. This indirect effect is caused by inertia and rational expectations and provides lower and more effective fluctuations on the interest rate.

In summary, a positive performance of the economy in terms of a high output or high real GDP translates into an increase in the inflation rate because economic expansion increases demand, while supply is usually not perfectly elastic. Therefore, prices increase in response to this demand increase and supply cannot grow at the same rate than demand. Moreover, the central bank reacts to this raise in inflation by increasing interest rates. If the monetary policy of the central bank is successful, it will decrease inflation at the expense of a decrease in the output or real GDP. Moreover, higher interest rates increase the exchange rate and, as a result, net exports weaken. In the rest of the paper, we study how a positive shock in the real GDP that leads to an increase in inflation and interest rates affects the valuation of highway infrastructure assets.

\section{Empirical analysis of the effect of inflation and interest rates on traffic: the 407 ETR case}

We first study the joint effect of inflation, nominal and real interest rates on traffic and tariff growth for a category 5 type of infrastructure asset: the highway 407 Express Toll Route (407 ETR) in Ontario, Canada. Highway 407 goes from Burlington to Oshawa through the Greater Toronto Area suburbs of Oakville, Mississauga, Brampton, Vaughan, Markham, Pickering and Whitby. The segment between Burlington and Pickering (107.9 km or $67.0 \mathrm{mi})$ is leased to and operated by a private concession company and it is known as the 407 ETR. 


\begin{tabular}{|c|c|c|c|c|c|c|}
\hline Variable & Definition & Obs. & Mean & Std. Dev. & Min. & Max. \\
\hline Revenue & Total monthly revenue & 168 & $54,200,000$ & $20,100,000$ & $24,200,000$ & $110,000,000$ \\
\hline $\mathrm{g}_{\text {revenue }}$ & Growth in monthly revenue & 167 & 0.0102 & 0.0684 & -0.1776 & 0.1712 \\
\hline $\mathrm{TR}_{\text {exc_TTC_VTC }}$ & $\begin{array}{l}\text { Total monthly revenue excluding } \\
\text { TTC and VTC }\end{array}$ & 168 & $41,200,000$ & $15,500,000$ & $15,900,000$ & $83,900,000$ \\
\hline TTC_VTC & $\begin{array}{l}\text { Monthly revenue from TTC and } \\
\text { VTC }\end{array}$ & 168 & $7,898,922$ & $3,739,996$ & $3,639,591$ & $17,500,000$ \\
\hline fees & Monthly revenue from fees & 168 & $5,048,594$ & $1,217,743$ & $3,456,181$ & $11,600,000$ \\
\hline avg_toll & Average toll price & 168 & 0.21 & 0.0600 & 0.12 & 0.34 \\
\hline avg_trip_length & Average trip length & 168 & 20.16 & 0.8600 & 18.08 & 22.61 \\
\hline trips & Number of trips & 168 & $9,311,412$ & $1,008,908$ & $6,698,980$ & $11,700,000$ \\
\hline VKT & vehicles-km & 168 & $188,000,000$ & $27,100,000$ & $121,000,000$ & $260,000,000$ \\
\hline inflation & Inflation from Canadian CPI (\%) & 156 & 0.14 & 0.3801 & -1.04 & 1.15 \\
\hline GDP & Canadian GDP & 157 & $1,487,990$ & 102,552 & $1,298,317$ & $1,663,948$ \\
\hline $\mathrm{g}_{\mathrm{GDP}}$ & Growth in Canadian GDP & 156 & 0.0016 & 0.0035 & -0.0138 & 0.0122 \\
\hline $\mathrm{r}_{\text {nominal }}$ & Nominal Canadian interest rate (\%) & 157 & 3.29 & 1.09 & 1.32 & 5.13 \\
\hline $\mathrm{r}_{\text {real }}$ & Real Canadian interest rate (\%) & 157 & 3.04 & 1.14 & 0.95 & 4.90 \\
\hline usd_cad & USD/CAD exchange rate & 106 & 1.08 & 0.10 & 0.96 & 1.37 \\
\hline eur_cad & EUR/CAD exchange rate & 106 & 1.43 & 0.10 & 1.23 & 1.66 \\
\hline
\end{tabular}

Table 1. Summary statistics. This table exhibits the summary statistics of the main variables that we use in our empirical analyses. The data period is March 2003- December 2016.

We use proprietary data on revenues, tolls and characteristics of the trips for the highway 407 ETR from March 2003 to December 2016. The macroeconomic data that we need for our analyses has been collected from the Bank of Canada and the Statistics Canada website. We employ data on Canadian inflation and Canadian GDP. Regarding the real interest rates, we use the "average yield (5 to 10 years) marketable bonds" from the Bank of Canada website. Finally, we use the exchange rates between the Canadian dollar and two currencies (the US dollar and the Euro) from the Bank of Canada. Monthly exchange rate data is only available from March 2007. Table 1 reports the summary statistics of the main variables that we use in our analysis.

Standard OLS regressions do not account for possible endogeneity problems and the reverse causality of the explanatory variables. For example, revenues from the infrastructure, inflation, GDP, and interest rates might be endogenously determined since they all depend on future expectations about economic activity. To address these issues, we base our main empirical methodology in a vector autoregression (VAR) model. This model allows us to estimate the joint dynamics of revenues from the infrastructure, inflation, GDP, real and nominal interest rates, and exchange rates as in Holtz-Eakin, Newey, and Rosen (1988) and Pesaran and Smith (1995). For a given set of variables, our VAR specification is given by:

$$
z_{t}=\beta_{0}+\beta_{1} z_{t-1}+\beta_{2} z_{t-2}+\beta_{3} z_{t-3}+\theta_{t}+\varepsilon_{t}
$$

where $z_{t}$ denotes the vector of endogenously determined variables (e.g., revenues from the infrastructure, inflation, growth in GDP, real and nominal interest rates, exchange rates, etc.) Notice that we will include different sets of variables in different parts of our econometric analysis and that we use 3 lags (i.e., $z_{t-1}, z_{t-2}$, and $z_{t-3}$ ) throughout the analyses. Let $\theta_{t}$ and $\varepsilon_{t}$ denote the monthly time-effects and the error term, respectively. 


\begin{tabular}{|c|c|c|c|c|c|}
\hline & & $\mathrm{g}_{\mathrm{VKT}}$ & inflation & $\mathbf{r}_{\text {nominal }}$ & $\mathbf{r}_{\text {real }}$ \\
\hline \multirow[t]{3}{*}{ gVKT } & lag 1 & $0.1680^{*}$ & $1.3209 * * *$ & $0.6734 * *$ & $0.8005^{* *}$ \\
\hline & $\operatorname{lag} 2$ & $0.4465^{* * *}$ & $1.2461^{* * *}$ & -0.0002 & 0.0457 \\
\hline & $\operatorname{lag} 3$ & $0.1695 *$ & -0.6952 & -0.2093 & 0.0226 \\
\hline \multirow[t]{3}{*}{ inflation } & lag 1 & $0.0462 * * *$ & $0.2000 * *$ & $0.1060 * *$ & $0.1375 * * *$ \\
\hline & $\operatorname{lag} 2$ & $0.0506^{* * *}$ & 0.0368 & 0.0155 & 0.0045 \\
\hline & $\operatorname{lag} 3$ & 0.0227 & -0.0730 & 0.0078 & 0.0101 \\
\hline \multirow[t]{3}{*}{$\mathbf{r}_{\text {nominal }}$} & $\operatorname{lag} 1$ & 0.1168 & 0.7492 & $0.9516^{* * *}$ & 0.1890 \\
\hline & $\operatorname{lag} 2$ & -0.0354 & -0.7392 & 0.2754 & 0.3409 \\
\hline & $\operatorname{lag} 3$ & -0.0354 & 0.2632 & -0.4238 & $-0.6141 *$ \\
\hline \multirow[t]{3}{*}{$\mathbf{r}_{\text {real }}$} & lag 1 & -0.1506 & -0.5294 & 0.0159 & $0.7961 * *$ \\
\hline & $\operatorname{lag} 2$ & 0.0795 & 0.3929 & -0.4496 & -0.5167 \\
\hline & $\operatorname{lag} 3$ & 0.0273 & -0.1082 & $0.4857 *$ & $0.6489 * *$ \\
\hline constant & & 0.21 & 15.92 & $76.42 * * *$ & $85.33 * * *$ \\
\hline Time FE & & Yes & & & \\
\hline Num. Obs. & & 116 & & & \\
\hline $\mathbf{R}^{2}$ & & 0.3736 & 0.2516 & 0.9725 & 0.9721 \\
\hline
\end{tabular}

Table 2. Multivariate VAR analysis with growth in VKT (vehicles kilometer traveled). This table shows the multivariate analysis of growth in traffic, inflation, nominal, and real interest rates. ${ }^{*},{ }^{* *}$, and ${ }^{* * *}$ indicate statistical significance at the $10 \%, 5 \%$, and $1 \%$ level, respectively

We first study the effect of inflation, and real and nominal interest rates on traffic growth in terms of vehicle kilometers traveled (VKT) and growth in tariffs in order to analyze the separate effects on quantities and prices, respectively. To do so, we run two separate multivariate VAR analyses. The first analysis includes the 4 following variables: the VKT growth in highway ETR 407, gVKT; inflation; the nominal interest rate rNOMINAL; and the real interest rate rREAL. Table 2 displays the results of this first analysis.

\begin{tabular}{|c|c|c|c|c|c|}
\hline & & $\mathbf{g}_{\text {Tariff }}$ & inflation & $\mathbf{r}_{\text {nominal }}$ & $\mathbf{r}_{\text {real }}$ \\
\hline \multirow[t]{3}{*}{$\mathbf{g}_{\text {Tariff }}$} & $\operatorname{lag} 1$ & $0.6817 * * *$ & -6.7455 & -2.3782 & -3.2375 \\
\hline & $\operatorname{lag} 2$ & $0.3304 * * *$ & 6.3021 & 5.2399 & 5.0861 \\
\hline & $\operatorname{lag} 3$ & -0.0471 & -0.8311 & -1.6519 & -0.0263 \\
\hline \multirow[t]{3}{*}{ inflation } & lag 1 & $0.0013 *$ & $0.1909 *$ & $0.1235^{* *}$ & $0.1729 * * *$ \\
\hline & $\operatorname{lag} 2$ & 0.0007 & 0.1159 & 0.0535 & 0.0461 \\
\hline & $\operatorname{lag} 3$ & -0.0008 & -0.0247 & 0.0086 & 0.0143 \\
\hline \multirow[t]{3}{*}{$\mathbf{r}_{\text {nominal }}$} & lag 1 & 0.0033 & 0.6497 & $1.0093 * * *$ & 0.2570 \\
\hline & $\operatorname{lag} 2$ & 0.0018 & -0.5102 & 0.2871 & 0.3325 \\
\hline & $\operatorname{lag} 3$ & -0.0060 & 0.2000 & -0.4524 & $-0.6102^{*}$ \\
\hline \multirow[t]{3}{*}{$\mathbf{r}_{\text {real }}$} & lag 1 & -0.0035 & -0.3537 & -0.0520 & $0.7075 * *$ \\
\hline & $\operatorname{lag} 2$ & -0.0016 & 0.0141 & -0.4859 & -0.5136 \\
\hline & $\operatorname{lag} 3$ & 0.0058 & 0.0509 & $0.5548^{*}$ & $0.6812 * *$ \\
\hline constant & & -0.82 & -33.17 & 103.56 & $125.57 *$ \\
\hline Time FE & & Yes & & & \\
\hline Num. Obs. & & 116 & & & \\
\hline $\mathbf{R}^{2}$ & & 0.9978 & 0.1310 & 0.9714 & 0.9704 \\
\hline
\end{tabular}

Table 3. Multivariate VAR analysis with growth in the average tariff. This table shows the multivariate analysis of growth in tariffs, inflation, nominal, and real interest rates. ${ }^{* * *}$, and ${ }^{* * *}$ indicates statjistical significance at the $10 \%, 5 \%$, and $1 \%$ level, respectively 
The second analysis includes the 4 following variables: the growth in tariffs in highway ETR 407, gTariff; inflation; the nominal interest rate $\mathrm{r}_{\mathrm{NOMINAL}}$; and the real interest rate $\mathrm{r}_{\mathrm{REAL}}$. Table 3 exhibits the results of this second analysis. Several results arise from these two tables. First, we show that past inflation has a strong positive effect on the growth in traffic (i.e., VKT) and a weak positive effect on the growth in tariffs. The coefficients 0.0462 and 0.0506 in Table 2 show that there is a positive and significant relationship between past inflation ( 1 and 2 months, respectively) and traffic growth. The coefficients 0.0013 and 0.0007 in Table 3 show that this positive relationship is weak for growth in tariffs.

Second, we show that there is a positive relation between traffic growth and both nominal and interest rates, but there is no relation between the growth in tariffs and interest rates. The coefficients 0.6734 for nominal interest rates and 0.8005 for real interest rates in Table 3 show their positive relationship with traffic growth, while the no significance of the coefficients -2.3782 and -3.2375 in Table 2 show the no relation between growth in tariffs and interest rates at the short-term period (less than 3 months).

Third, we also show that there is a significantly positive autocorrelation in traffic up to 3 months, that is, if VKT increases today, then VKT will most likely increase during the next 3 months. The coefficients $0.1680,0.4465$, and 0.4695 in Table 2 display this positive autocorrelation for 1, 2, and 3 months. Similarly, there is a significantly positive autocorrelation in tariffs up to 2 months. The coefficients 0.6817 and 0.3304 in Table 2 display this positive autocorrelation for 1 and 2 months.

Although the interesting results for our analysis arise when we study the separate effects on traffic and tariffs, we also perform an analysis with of the effect of inflation, and real and nominal interest rates on the revenue growth of the ETR 407 (see Appendix A). ${ }^{1}$ This analysis shows that there is a positive and significant relationship between the past and current growth in revenue, which indicates that the growth in revenues is persistent, that is, when there is a period of positive (negative) growth in revenues, the probability that the revenue growth is positive (negative) in the following months is high. We also find that the revenue growth in the recent past is positively related to current inflation, which corroborates the persistence in revenue growth. Moreover, we find that revenue growth and interest rates are positively related, but the positive (negative) growth in revenues anticipates the increase (decrease) in interest rates. The lagged effects that we obtain from these results are consistent with the macroeconomic framework and the monetary policy transmission channels that we discussed in section 2. In particular, notice that the growth in revenues and the increase in inflation lead the increase in nominal and real interest rates.

Moreover, VAR models can be used to estimate the reaction of a particular endogenous variable to a shock in another endogenous variable. Figure 3 displays impulse-response graphs with the response of the highway 407 ETR revenue growth over 12 months to a one standard deviation shock to inflation and the nominal interest rate. It also shows the $95 \%$ bootstrapped confidence intervals (CI) based on 1000 simulations. These results confirm some of our findings from the previous VAR analysis. First, revenue is positively related to inflation. Second, nominal interest rates do not predict growth in revenue. These shocks are persistent. Specifically, the increase in revenue growth in the highway 407 ETR from a shock of one standard deviation in inflation is still present six months after the shock.

1 We show the main results with traffic (quantities) and tariffs (prices) in separate tables instead of analyzing total revenues, which account for both traffic and tariffs. The reason behind this split is that infrastructure assets of category 5 present free adjustable tariffs. Therefore, the current tariff could be below the tariff that reflects the willingness-to-pay of the infrastructure users. For example, the fact that ETR 407 shows an increase in traffic (i.e., an increase in VKT) even when there is an increase in tariffs during economic recessions suggests that the tariffs of this infrastructure are lower than the optimal tariff that the operator could charge in order to maximize its profits. 

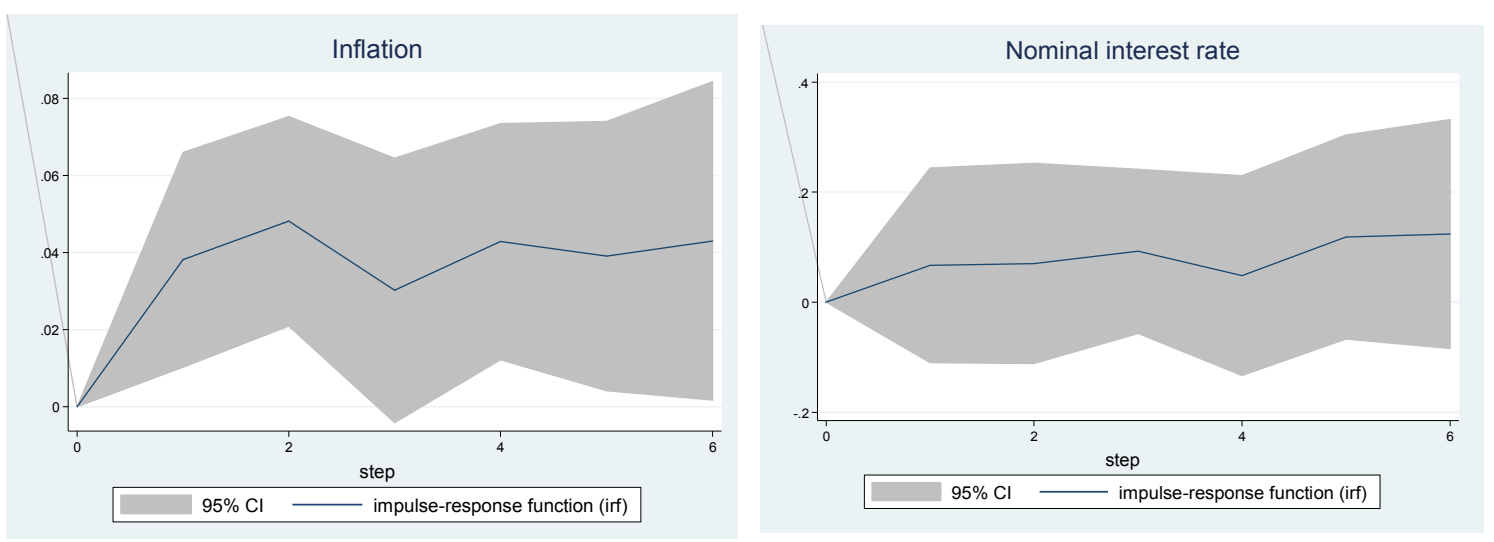

Figure 3. Impulse-response functions. This figure displays impulse-response functions with the responses of the highway 407 ETR revenue growth over 12 months to a one standard deviation shock to inflation and the nominal interest rate.

Figure 4 shows how economic activity affects the value of infrastructure assets of category 5 and summarizes the channels that drive the value of these assets. The economic intuition goes as follows. In a period of expansion of the economy the real GDP increases, which increases the output gap and, equivalently, increases demand. Because the supply of most assets, goods and services is inelastic (or limited in some corridors, for example, in the Toronto 401/407 corridor), prices go up. In the aggregate, inflation in the economy goes up. The central bank reacts to this raise in inflation by increasing the short-term nominal interest rate to meet its target real interest rate.

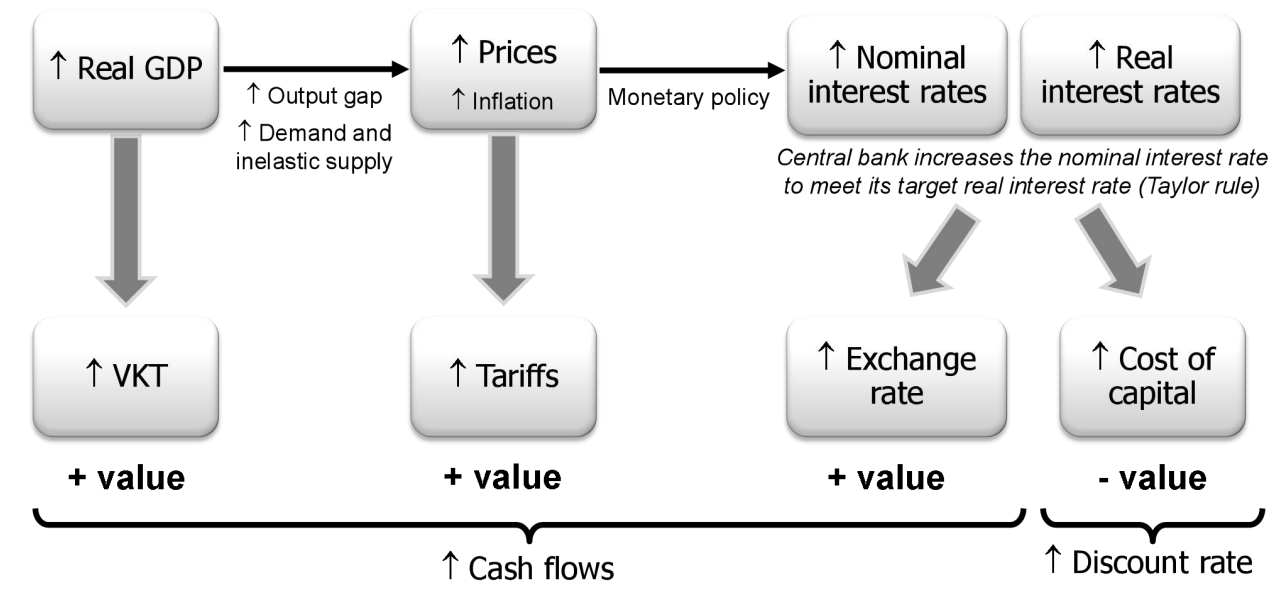

Figure 4. Channels that drive the value of infrastructure assets of category 5 . This figure shows how economic activity affects the value of infrastructure assets of category 5 and exhibits the channels that drive the value of this type of assets.

How does this affect infrastructure assets of category 5. An increase in real GDP in the area increases traffic (i.e., vehicle kilometers traveled, VKT). Moreover, an increase in prices in the economy allows the operator to increase in tariffs because users present a higher willingness to pay. See Appendix B for an analysis of the relationship of local GDP on traffic, tariffs, and revenues for the 407 ETR.Both the increase in traffic and in tariffs increase the cash flows generated by the infrastructure assets and ceteris paribus it increases its value. However, an increase in nominal and real interest rates increases the exchange rate and the cost of capital. Therefore, an increase in the cost of capital increases the discount rate and ceteris paribus it decreases the value of the infrastructure asset.

The empirical results that we have provided show that, when interest rates increase, then the increase in the value of the 407 ETR from the increase in cash flows is higher than the decrease in value from the increase in the discount rate. In the following section, we will setup and solve a partial equilibrium model for the valuation of the 5 different categories of infrastructure assets in order to study the effects of the economic activity in the value of these different assets. 


\section{Economic activity and the valuation of different types of infrastructure assets: a structural model}

In the previous section, we have empirically analyzed the effects of economic activity on a specific category 5 infrastructure asset. In this section, we set up and develop a parsimonious valuation model of infrastructure assets to compare the effects of economic activity on the value of assets across the 5 types of infrastructure assets that we described in section 1 . We assume that the value of an infrastructure asset, $V$, is determined by all the free cash flows that it can generate in the future, discounted at its weighted average cost of capital as follows:

$$
V=\sum_{t=0}^{T} \frac{F C F_{t}}{1+W A C C_{t}}
$$

where $F C F_{t}$ is the free cash flow at any time $t$, WACC $\mathrm{t}_{\mathrm{t}}$ is the weighted average cost of capital, and $T$ is the terminal period of the asset or the end of the concession. ${ }^{2}$

To be able to compare among the different categories of assets, we assume that there is one infrastructure asset and we analyze the impact of interest rate changes in its value in the 5 different categories of assets that we described above. We assume that the asset produces the same initial FCF (e.g., FCF at year 0 is CAD 100,000,000) and the cost of capital that investors will apply to the cash flows that it generates is the same in the 5 categories. The main difference among the 5 categories of assets is the free cash flows that they produce. Table 4 summarizes the assumptions about the free cash flows of the 5 categories of assets.

\begin{tabular}{ll} 
Asset category & Growth in free cash flows \\
\hline Category 1 & $0 \%$ \\
Category 2 & Inflation \\
Category 3 & Inflation and traffic growth \\
Category 4 & max(Inflation; GDP per capita growth) and traffic growth \\
Category 5 & Growth in WTP and traffic growth \\
\hline
\end{tabular}

Table 4. Assumptions about the free cash flows of the 5 categories of assets. This table shows the description of the growth in free cash flows that the model assumes for the different categories of infrastructure assets

We assume that the concession will end in 50 years from now and presents a leverage that is defined by a constant debt to value ratio of 0.50 . We assume a Taylor rule as in Taylor (1999) such that inflation $=\left(\right.$ interest rate $\left.-\alpha_{1}\right) / \alpha_{2}+\alpha_{3}$. We assume that GDP growth is a linear function of interest rates and inflation such that GDP growth $=\delta_{0}+\delta_{1} *_{\text {interest }}$ rate $+\delta_{2} *$ inflation. We also consider a traffic growth factor of Y times the GDP growth and a GDP growth per capita equal to $\mu_{1}+\mu_{2} * G D P$ growth. Table 5 summarizes the parameterization of the model.

\footnotetext{
${ }^{2}$ Note that it is standard to compute the total value of an asset as the sum of expected free cash flows that this asset will produce discounted at the WACC. Equivalently, one could estimate the value of the equity of this asset using the dividend discount model (DDM) and, then, add its debt to obtain its total value.
} 


\begin{tabular}{ll} 
Parameter & Value \\
\hline Initial free cash flows (millions of CAD) & 100 \\
Years to end concession (years) & 50 \\
Inflation parameters: & \\
$\alpha_{1}$ & -0.04 \\
$\alpha_{2}$ & 1.50 \\
$\alpha_{3}$ & 0.02 \\
GDP growth parameters: & \\
$\delta_{0}$ & 0.01 \\
$\delta_{1}$ & 0.2 \\
$\delta_{2}$ & 0.9 \\
Traffic growth parameter: & \\
& \\
GDP per capita growth parameters: & 0.4 \\
$\quad 1$ & \\
2 & 0.005 \\
Growth in willingness-to-pay parameter: & 0.9 \\
$\theta$ & \\
WACC parameters: & 1.2 \\
Beta & \\
Market risk premium & $30 \%$ \\
Tax rate & $4 \%$ \\
Debt premium & \\
\hline
\end{tabular}

Table 5. Parameters of the model. This table displays the baseline parameterization of the model

We estimate the value of the different categories of infrastructure assets for different levels of the risk-free rate ranging from $1 \%$ to $7 \%$. Figure 5 exhibits the results of this valuation. We normalize the results to investing 100 units of currency in each category of infrastructure in a scenario of interest rates of $1 \%$. Then we can analyze how the value of each category changes with an increase in interest rates. Several conclusions arise from this figure. First, the values of infrastructure assets of categories 1 and 2 decrease with an increase in interest rates. This result indicates that the discount rate effect dominates the cash flow effect for infrastructure assets of categories 1 and 2.

Second, the decrease in value with an increase in interest rates is lower for assets of category 2 than the decrease for category 1 assets because cash flows of the former can increase with inflation while cash flows of the latter are constant. Therefore, the cash flow effect is higher for assets of category 2 than for assets of category 1.

Third, the effect of interest rates in the value of assets of category 3 is low. This result suggests that the discount rate has an effect of slightly lower magnitude than the cash flow effect. The results from the parameterization of the model show that a $6 \%$ increase in interest rates from $1 \%$ to $7 \%$ for assets of this category would increase the value of the asset by $13 \%$.

Fourth, the magnitude of the effect of interest rates in the value of assets of category 4 is relevant. Therefore, the discount rate has an effect of lower magnitude than the cash flow effect for this category of assets. The results from the model show that a $6 \%$ increase in interest rates from $1 \%$ to $7 \%$ would increase the value of the asset by $21 \%$.

Fifth, there is a high positive relationship between interest rates and the value of assets of category 5 because the cash flow effect clearly dominates the discount rate effect for this category of assets. The results from the model show that a $6 \%$ increase in interest rates from $1 \%$ to $7 \%$ would increase the value of the asset by $61 \%$. Overall, the value of 
asset categories 4 and 5 increase with interest rates, while the value of asset categories 1 and 2 decrease.

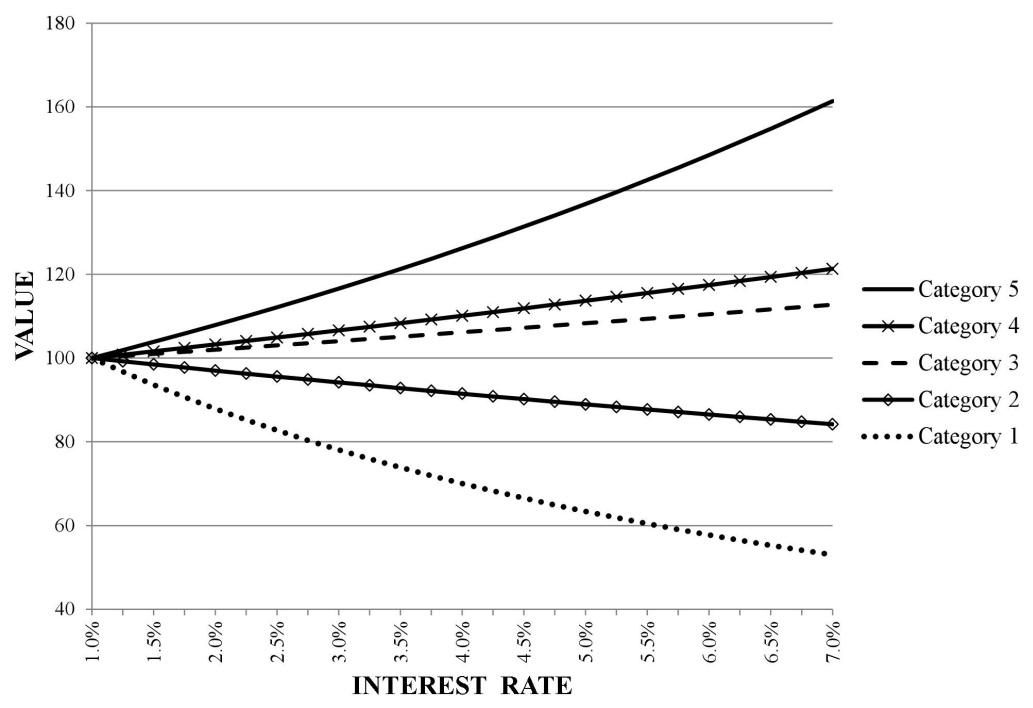

Figure 5. The effect of interest rates in the value of 5 categories of infrastructure assets. This figure shows how the value of an investment of CAD 100 million in an economy with a risk-free interest rate at $1 \%$ changes when there is a permanent increase in the risk-free rate for the 5 categories of infrastructure assets.

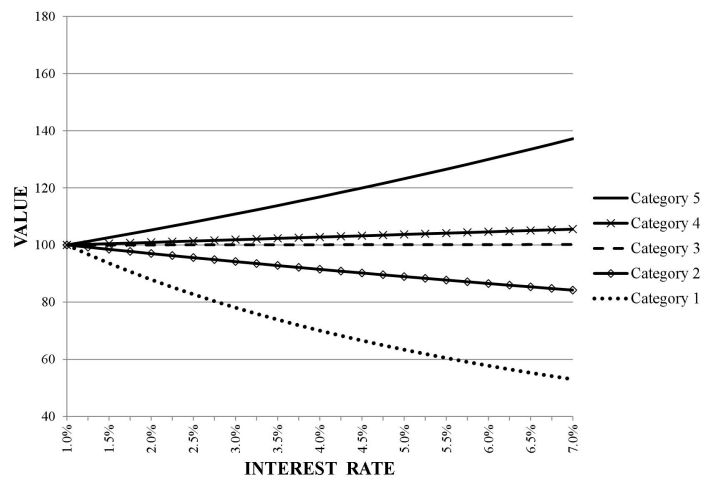

$$
\gamma=0.25
$$

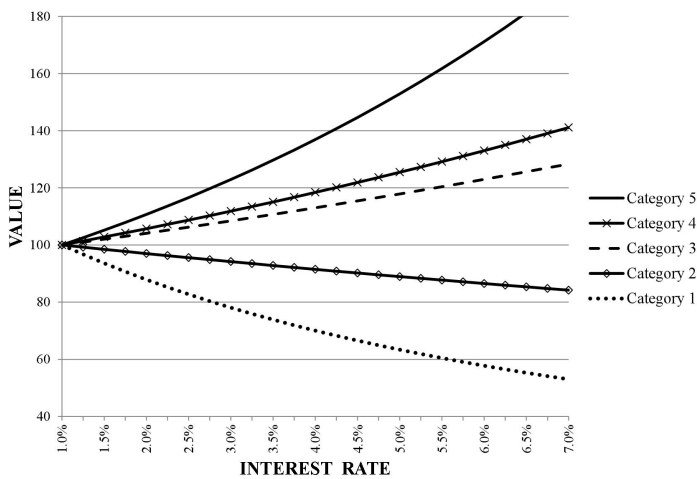

$\gamma=0.55$

Panel A. Sensitivity to traffic growth parameter

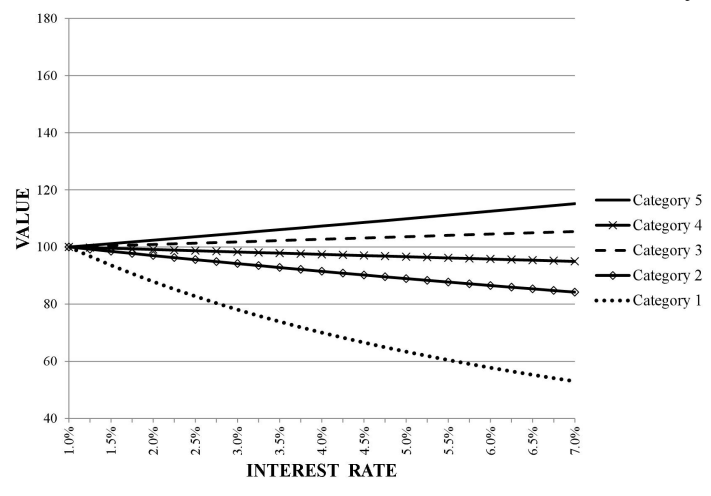

$\delta_{1}=0.1$ and $\delta_{2}=0.8$



$\delta_{1}=0.3$ and $\delta_{2}=1.0$

Panel B. Sensitivity to GDP growth parameters 


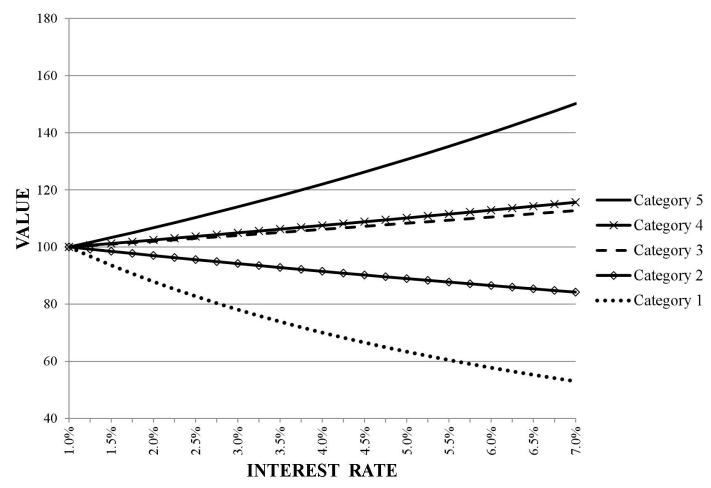

$\mu_{1}=0.000$ and $\mu_{2}=0.85$

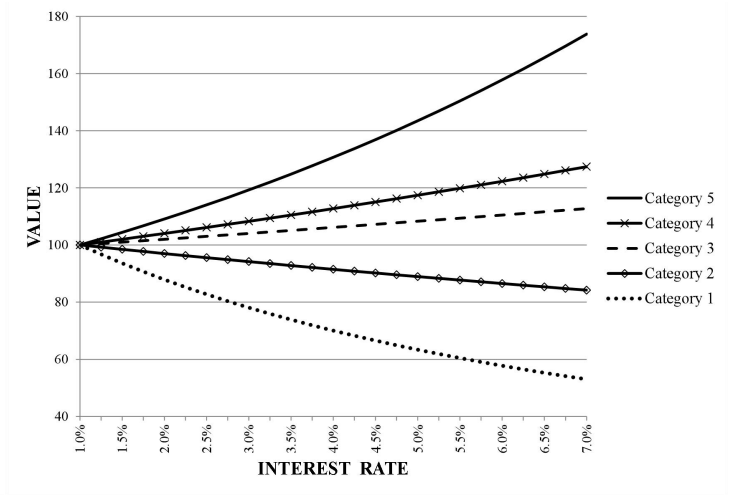

$\mu_{1}=0.010$ and $\mu_{2}=0.95$

Panel C. Sensitivity to GDP per capita growth parameters

Figure 6. Sensitivity analysis to the key parameters of the parameterization. This figure shows the sensitivity of the value of the infrastructure to the traffic growth parameters (Panel A), the GDP growth parameters (Panel B), and the GDP per capita growth parameters (Panel C).

Finally, we run a sensitivity analysis to the key parameters of the model. Figure 6 shows the results of this analysis. We specifically analyze the sensitivity to the traffic growth parameters (Panel A), the GDP growth parameters (Panel B), and the GDP per capita growth parameters (Panel C). Overall, we observe that the values of the infrastructure assets of categories 3, 4, and 5 are the most sensitive to different parameters related to traffic growth, GDP growth, and GDP per capita growth. Most importantly, the trend of the relationship between interest rates and value of the infrastructure does not change for any type of asset, except for category 3 that goes from a positive to a negative relationship when we decrease the GDP growth parameters (Panel B; left).

\section{Conclusions}

Changes in interest rate have an effect on the value of infrastructure assets. On the one hand, an increase in interest rates decreases the value of infrastructure assets because it decreases the present value of their cash flows (the discount rate effect). On the other hand, increases in interest rates are usually related to increases in economic activity because central banks increase interest rates as a response to increases in inflation provoked by economic expansions. Therefore, an increase in interest rates increases the value of infrastructure assets because it increases the value of their cash flow (the cash flow effect).

In this paper we have analyzed whether the discount effect dominates the cash flow effect. We find that the cash flow effect dominates the discount rate effect for assets with tariffs that can be adjusted to manage demand (e.g., adjustable-rate toll roads) and, therefore, the value of these assets increases in periods of increasing interest rates and economic expansion. Nevertheless, the opposite occurs for assets that do not bear demand risk (e.g., non-toll roads), in which the value of these assets decreases.

Further research could address the effects of exchange rates on the performance of infrastructure assets. For example, if the US and Canadian economies are expected to grow at a higher rate than the Euro zone, then the USD and CAD would increase their value with respect to the EUR. Therefore, an investor based in the European Union using the euro as a base currency could benefit from investing in infrastructure assets located in the US or Canada (and, therefore, with revenues collected in USD and CAD, respectively) not only because the US and Canadian economies are performing well, but because the increase in the exchange rates of the USS and CAD with respect to the EUR.

\section{References}

1. Banky RB. The Fisher hypothesis and the forecastability and persistence of inflation. Journal of Monetary Economics.1987; 19: 3-24.

2. Fama EF. (1975) Short term interest rates as predictors of inflation. American Economic Review.1975; 65: $269-282$ 
3. Fama EF, Gibbons MR. Inflation, real returns and capital investment. Journal of Monetary Economics.1982; 9: 297-324.

4. Fisher I. The theory of interest. Macmillan. New York, NY. 1930.

5. Holtz-Eakin D, Newey W, Rosen HS. Estimating vector autoregressions with panel data. Econometrica.1988; 56 (6): 1371-95.

6. Huizinga J, Mishkin FS. Inflation and real interest rates on assets with different risk characteristics. The Journal of Finance, 1984; 39: 699-712.

7. Hutzinga J, Mishkin FS. Monetary policy regime shifts and the unusual behavior of real interest rates. Carnegie-Rochester Conference Series on Public Policy.1986; 24: 231-274.

8. Kamin SB, Rogers JH. Output and the real exchange rate in developing countries: an application to Mexico. Journal of Development Economics 61.1 (2000): 85-109.

9. Lee B. Causal relations among stock returns, interest rates, real activity, and inflation. The Journal of Finance, 2002; 47: 1591-1603.

10. Mendoza EG. The terms of trade, the real exchange rate, and economic fluctuations. International Economic Review.1995;101-137.

11. Mishkin FS. The real rate of interest: An empirical investigation. The cost and consequences of inflation. Carnegie-Rochester Conference Series on Public Policy.1981; 15: 151-200.

12. Mishkin, FS. Understanding real interest rates. American Journal of Agricultural Economics. 1988; 70: 1064-1072.

13. Mishkin FS. Is the Fischer effect for real. A reexamination of the relationship between inflation and interest rates. Journal of Monetary Economics. 1992; 30: 195-215.

14. Nelson CR, Schwert GW. Short-term interest rates as predictors of inflation: On testing the hypothesis that the real rate of interest is constant. American Economic Review. 1977; 67: 478-486.

15. Pesaran M, Hashem, Ron Smith. Estimating long-run relationships from dynamic heterogeneous panels. Journal of Econometrics. 1995;68 (1): 79-113.

16. Summers LH. The non-adjustment of nominal interest rates: A study of the Fisher effect in: James Tobin. ed., A symposium in honor of Arthur Okun (Brookings Institution Washington, DC). 1983

17. Taylor JB. The robustness and efficiency of monetary policy rules as guidelines for interest rate setting by the European Central Bank. Journal of Monetary Economics. 1999; 43.3: 655-679.

18. Taylor JB. Teaching modern macroeconomics at the principles level. American Economic Review. 2000; 90.2: 90-94.

19. Taylor JB. The role of the exchange rate in monetary-policy rules. American Economic Review. 2001; 91.2: 263-267. 


\section{Appendix A. Univariate and Multivariate Analyses of Revenue Growth}

We run 1 univariate VAR analysis and 4 bivariate VAR analyses using the following specifications: [1] the growth in the monthly revenues in highway ETR 407 only, gREVENUE; [2] gREVENUE and inflation; [3] gREVENUE and GDP growth, $\mathrm{g}_{\text {GDP }}$; [4] $\mathrm{g}_{\text {ReVEnUE }}$ and the nominal interest rate $\mathrm{r}_{\text {NOMinaL }}$; and [5] $\mathrm{g}_{\text {REVEnUE }}$ and the real interest rate $\mathrm{r}_{\text {ReAl. }}$. Table A1 exhibits the results of these 5 specifications.

Six main results arise from these analyses. First, lagged revenue growth predicts current revenue growth up to three months across all the 5 specifications. The coefficients are statistically significant for all the specifications. Second, past inflation is positively related to current growth in revenues. This effect is significant up to 2 months. Third, past growth in revenue is also positively related to current inflation up to 2 months. Fourth, the relationship between the revenue growth and past GDP growth is weak. Later in the analysis, we will focus on the study of the correlation structure of revenue growth and GDP. Fifth, nominal interest rates and real interest rates do not predict growth in revenue. Sixth, both nominal and real interest rates present a strong one-month autocorrelation. These results are one-to-one (specification [1]) and bivariate (specifications [2-5]). Next step is to study the full multivariate model with all the endogenous variables together, that is, growth in revenue, inflation, GDP growth, nominal interest rates, and real interest rates. Table $\mathbf{A 2}$ displays the results of this VAR specification.

The main results from Table A2 are the following. First, there is a positive and significant relationship between the past and current growth in revenue. Specifically, we obtain that the 2 and 3 months lagged growth in returns forecasts $44.3 \%$ and $40.2 \%$ of the current growth in revenues, respectively. This result indicates that the growth in revenues is persistent, that is, when there is a period of positive (negative) growth in revenues, the probability that the revenue growth is positive (negative) in the following months is high. Second, we find that recent past inflation has a positive effect on revenue growth. This result indicates that revenues grow in periods of increasing prices in the economy. We also find that the revenue growth in the recent past is positively related to current inflation, which corroborates the persistence in revenue growth. Third, we do not find any significant effect of past real nor nominal interest rates on revenue growth. However, we do find a positive relationship between the revenue growth in the past month and the current nominal and real interest rates. This result indicates that revenue growth and interest rates are positively related, but the positive (negative) growth in revenues anticipates the increase (decrease) in interest rates. The lagged effects that we obtain from these results are consistent with the macroeconomic framework and the monetary policy transmission channels that we discussed in section 2. In particular, notice that the growth in revenues and the increase in inflation lead the increase in nominal and real interest rates. 


\begin{tabular}{|c|c|c|c|c|c|c|c|c|}
\hline & & [1] & [2] & & [3] & & [4] & \\
\hline & & $\mathrm{g}_{\text {revenue }}$ & $\mathrm{g}_{\text {revenue }}$ & inflation & $\mathrm{g}_{\text {revenue }}$ & $\mathrm{r}_{\text {nominal }}$ & $\mathrm{g}_{\text {revenue }}$ & $\mathrm{r}_{\text {real }}$ \\
\hline \multirow[t]{3}{*}{ grevenue $_{\text {e }}$} & lag 1 & $0.2549 * * *$ & 0.0734 & $1.4072 * * *$ & $0.2518^{* * *}$ & $0.9900 * * *$ & $0.2541 * * *$ & $1.1088^{* * *}$ \\
\hline & $\operatorname{lag} 2$ & $0.4959 * * *$ & $0.3984 * * *$ & $1.9547 * * *$ & $0.5062 * * *$ & 0.0465 & $0.5159 * * *$ & -0.037 \\
\hline & $\operatorname{lag} 3$ & $0.3910^{* * *}$ & $0.3820 * * *$ & -0.1757 & $0.3902 * * *$ & -0.3998 & $0.3954 * * *$ & -0.0954 \\
\hline \multirow[t]{3}{*}{ inflation } & lag 1 & & $0.0358 * *$ & $0.1834 * *$ & & & & \\
\hline & $\operatorname{lag} 2$ & & $0.0390 * * *$ & 0.0317 & & & & \\
\hline & lag 3 & & 0.0104 & -0.0849 & & & & \\
\hline \multirow[t]{3}{*}{$\mathbf{r}_{\text {nominal }}$} & lag 1 & & & & -0.0196 & $0.9799 * * *$ & & \\
\hline & $\operatorname{lag} 2$ & & & & 0.0324 & -0.1562 & & \\
\hline & $\operatorname{lag} 3$ & & & & -0.0125 & 0.0368 & & \\
\hline \multirow[t]{3}{*}{$\mathbf{r}_{\text {real }}$} & lag 1 & & & & & & -0.2383 & $0.9907 * * *$ \\
\hline & $\operatorname{lag} 2$ & & & & & & 0.0274 & -0.209 \\
\hline & $\operatorname{lag} 3$ & & & & & & -0.0066 & 0.0746 \\
\hline constant & & 0.4390 & 0.6406 & 24.76 & -0.0467 & 75.67 & 1.8931 & 82.43 \\
\hline Time FE & & Yes & Yes & Yes & Yes & Yes & Yes & Yes \\
\hline Num. Obs. & & 125 & 116 & 116 & 116 & 116 & 116 & 116 \\
\hline $\mathbf{R}^{2}$ & & 0.295 & 0.365 & 0.213 & 0.285 & 0.971 & 0.285 & 0.969 \\
\hline
\end{tabular}

Table A1. Univariate and bivariate VAR analysis. Specification [1] studies the univariate effects of growth in revenues with lags up to 3 months. [2] shows the bivariate analysis of growth in revenues and inflation. [3] shows the bivariate analysis of growth in revenues and nominal interest rates. [4] shows the bivariate analysis of growth in revenues and real interest rates. All the specifications include time fixed effects. *,**, and *** indicates statistical significance at the $10 \%, 5 \%$, and $1 \%$ level, respectively.

\begin{tabular}{llllll} 
& & grevenue & inflation & $\mathbf{r}_{\text {nominal }}$ & $\mathbf{r}_{\text {real }}$ \\
\cline { 3 - 6 } grevenue & $\operatorname{lag} 1$ & 0.0504 & $1.2088^{* *}$ & $0.7290^{* *}$ & $0.8687^{* *}$ \\
& $\operatorname{lag} 2$ & $0.4386^{* * *}$ & $1.7818^{* * *}$ & 0.0221 & -0.0041 \\
inflation & $\operatorname{lag} 3$ & $0.3997^{* * *}$ & -0.0327 & -0.3565 & -0.1772 \\
& $\operatorname{lag} 1$ & $0.0383^{* * *}$ & $0.1774^{* *}$ & $0.1124^{* *}$ & $0.1425^{* * *}$ \\
& $\operatorname{lag} 2$ & $0.0462^{* * *}$ & 0.0536 & 0.0148 & -0.0021 \\
$\mathbf{r}_{\text {nominal }}$ & $\operatorname{lag} 3$ & 0.0122 & -0.0786 & 0.0158 & 0.0179 \\
& $\operatorname{lag} 1$ & 0.0998 & 0.7586 & $0.9702^{* * *}$ & 0.1859 \\
& $\operatorname{lag} 2$ & 0.0011 & -0.6939 & 0.2502 & 0.3215 \\
$\mathbf{r}_{\text {real }}$ & $\operatorname{lag} 3$ & -0.0692 & 0.1871 & -0.4061 & $-0.5788^{*}$ \\
& $\operatorname{lag} 1$ & -0.1315 & -0.5468 & -0.0093 & $0.7936^{* *}$ \\
& $\operatorname{lag} 2$ & 0.0230 & 0.3142 & -0.4039 & -0.4782 \\
constant & $\operatorname{lag} 3$ & 0.0770 & 0.0043 & 0.4564 & $0.6036^{*}$ \\
Time FE & & 1.15 & 18.57 & $75.27^{* * *}$ & $83.76^{* * *}$ \\
Num. Obs. & & Yes & & & \\
$\mathbf{R}^{2}$ & & 0.3933 & 0.2410 & 0.9726 & 0.9720 \\
\hline
\end{tabular}

Table A2. Multivariate VAR analysis with growth in revenues. This table displays the joint effects of growth in revenues, inflation, nominal interest rates, and real interest rates. ${ }^{* * *}$, and ${ }^{* * *}$ indicates statistical significance at the $10 \%, 5 \%$, and $1 \%$ level, respectively 


\section{Appendix B. Analysis of the relationship of local economic activity on traffic, tariffs, and revenues}

In this appendix, we further analyze the relationship of local GDP and the performance of the infrastructure asset. We study the relationship between local economic activity measured in terms of employment growth in the Toronto area and the following three measures: (1) growth in revenues; (2) growth in traffic in terms of VKT; and (3) growth in tariffs. Table B1 exhibits the results of this analysis and shows that there is a positive relationship among GDP growth (measured in terms of employment growth in the Toronto area), growth in traffic, and growth in tariffs.

\begin{tabular}{|c|c|c|c|c|c|c|}
\hline \multirow{2}{*}{ 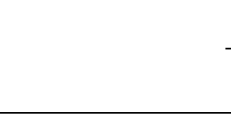 } & \multicolumn{2}{|l|}{ [1] } & \multicolumn{2}{|l|}{ [2] } & \multicolumn{2}{|l|}{ [3] } \\
\hline & $\mathrm{g}_{\text {revenue }}$ & gemployment & $\mathrm{g}_{\mathrm{VKT}}$ & gemployment & $\mathrm{g}_{\text {Tariff }}$ & gemployment \\
\hline grevenue(lag 1) & 0.1058 & $0.0224 * * *$ & & & & \\
\hline $\mathbf{g}_{\mathrm{VKT}}$ & & & 0.0262 & $0.0221 * * *$ & & \\
\hline $\mathbf{g}_{\text {Tariff }}$ & & & & & $0.7853 * * *$ & 0.0547 \\
\hline gemployment $(\operatorname{lag} 1)$ & 0.2107 & $0.5286^{* * *}$ & 1.5908 & $0.4947 * * *$ & $0.2530^{* * *}$ & $0.5678^{* * *}$ \\
\hline constant & -1.3827 & 0.1137 & -0.3259 & 0.0960 & $-6.9026 * * *$ & 1.7608 \\
\hline Time FE & Yes & & Yes & & Yes & \\
\hline Num. Obs. & 120 & & 120 & & 120 & \\
\hline $\mathbf{R}^{2}$ & 0.0102 & 0.4023 & 0.0177 & 0.4160 & 0.0102 & 0.4023 \\
\hline
\end{tabular}

Table B1. Relationship of local GDP and the performance of the infrastructure asset. This table shows the of local economic activity measured in terms of employment growth in the Toronto area with growth in revenues (specification ${ }^{[1]}$ ), growth in VKT (specification ${ }^{[2]}$ ), and the growth in the average tariff $\left(\right.$ specification $^{[3]}$ ) in the $407 \mathrm{ETR}^{*}{ }^{* * *},{ }^{*}$, and ${ }^{* * *}$ indicates statistical significance at the $10 \%, 5 \%$, and $1 \%$ level, respectively 